Article

\title{
More Than Four Walls: The Meaning of Home in Home Birth Experiences
}

\author{
Emily Burns
}

Religion and Society Research Centre, School of Social Sciences and Psychology, University of Western Sydney, Penrith, NSW 2750, Australia; E-Mail: emily.burns@uws.edu.au

Submitted: 1 November 2014 | In Revised Form: 11 January 2015 | Accepted: 13 January 2015 |

Published: 9 April 2015

\begin{abstract}
The "home versus hospital" as places of birth debate has had a long and at times vicious history. From academic literature to media coverage, the two have often been pitted against each other not only as opposing physical spaces, but also as opposing ideologies of birth. The hospital has been heavily critiqued as a site of childbirth since the 1960s, with particular focus on childbirth and medicalisation. The focus of much of the hospital and home birthing research exists on a continuum of medicalisation, safety, risk, agency, and maternal and neonatal health and wellbeing. While the hospital birthing space has been interrogated, a critique of home birthing space has remained largely absent from the social sciences. The research presented in this article unpacks the complex relationship between home birthing women and the spaces in which they birth. Using qualitative data collected with 59 home birthing women in Australia in 2010, between childbearing and the home should not be considered as merely an alternative to hospital births, but rather as an experience that completely renegotiates the home space. Home, for the participants in this study, is a dynamic, changing, and even spiritual element in the childbirth experience, and not simply the building in which it occurs.
\end{abstract}

\section{Keywords}

birth; home; hospital; medicalisation; place; space

\section{Issue}

This article is part of the special issue "Housing and Space: Toward Socio-Spatial Inclusion", edited by Dr. Dallas Rogers (University of Western Sydney, Australia), Dr. Rae Dufty-Jones (University of Western Sydney, Australia) and Dr. Wendy Steele (RMIT University, Australia).

(C) 2015 by the author; licensee Cogitatio (Lisbon, Portugal). This article is licensed under a Creative Commons Attribution 4.0 International License (CC BY).

\section{Introduction}

In popular and medical childbirth discourse the home is not only constructed as "other" than the hospital (Homer et al., 2014), but also as the place of risk as opposed to safety (Lane, 1995; Possamaï-Inesedy, 2006). While much of the research on home birth focuses on why women choose to birth at home (Catling, Dahlen, \& Homer, 2014; Moore, 2011), this article demonstrates that their experiences can tell us much about the negotiation of power and the management of bodies within the spaces that home birthing is performed. Indeed, the medicalisation of childbirth is now a wellknown and widely used concept in disciplines and subdisciplines from sociology, anthropology, women's studies, midwifery and nursing. The medicalisation thesis has become so dominant that its importance has overshadowed the need to be equally as rigorous in analyses of the dynamics at play in home birthing space.

Most commonly, the home is conceptually understood within domestic or "ordinary" living space. In the birth literature, it is often regarded as the "backdrop" in which birth takes place, though there are some notable exceptions to this (Fannin, 2003; Michie, 1998). Indeed for Putnam (1999), when a new mode of living is mapped onto a house or a new house mapped onto an existing mode of living, the meaning of domestic space is redefined. In this light, what we know about the home, and about women's relationships with the 
home, will undoubtedly be entirely different from what we need to know about the home when remapped for childbirth, and the impact this experience has on the home and the birthing woman and her family thereafter.

That the focus of the home/hospital debate is centralised around place, and the spatial differentiation between the two, indicate clearly not only the pragmatic differences between the two sites as birth places, but the ideological distance that can so easily be epitomised by two discursively oppositional terms. The home and the hospital have become polar opposites in the discourse on childbirth (Powell Kennedy, Nardini, McLeod-Waldo, \& Ennis, 2009; Reibel, 2004).

Cresswell (1996) writes about the construction of ideologies, the most important ingredient of which, he argues, is the differentiation by place (p. 153). This is clearly evident in the home/hospital birth dichotomy, primarily because the hospital is what Cresswell (via Bourdieu) refers to as "doxa", meaning it has become part of everyday common sense rather than critical decision making. At the opposite end, then, home is specifically differentiated as "abnormal", and the spatial differentiation comes to personify this oppositional relationship, signifying ideological differences as well, specifically through the focus of safety and risk, which both sides of the debate used to defend their position (Michie, 1998).

This article will move beyond notions of safety and risk, and present findings on home that focus on the intimate and complex ways the home is reimagined in home birth experiences. I argue here that the home is far from merely the backdrop of childbirth, nor is it a site that simply opposes medical intervention. The role and importance of place attachment and the new meanings and boundaries that home birth instigates renegotiates the way birthing women relate to their homes and in turn, their births.

\section{Background}

Because reproduction is said to form the nexus of nature and society, the way a culture handles birth is strongly indicative of its core values (Blaaka \& Shauer, 2008; Davis-Floyd, 1993/2008; Rapp, 2001). DavisFloyd (1994) sees these values played out in the ritualistic procedures of birth, particularly in hospital settings. The hospital has been heavily critiqued as a site of childbirth since the 1960s, and scholars have primarily drawn on medicalisation as the framework for interrogation. Medicalisation can be defined here as,

the expansion of medical jurisdiction into the realms of other previously non-medically defined problems...a process which clearly serves the interests of medicine with its increasing focus on the indicators of disease rather than the individual's experience of health and illness (Cahill, 2001, p. 339).
It is important to note however, that in the context of childbirth not all medicalised experiences are necessarily negative ones, however the assumption of control by medicine results in an implicit hand-over of bodily agency, which in turn can lead to disempowerment (Cahill, 2001; Davis-Floyd, 1993/2008; Williams \& Umberson, 1999). The biomedical preference for understanding women ignores the inescapable psychosocial elements of birth (Mansfield, 2008), and the important transition to motherhood (Cahill, 2001). The dominance of medicine has resulted in a feminist response to the configuration of the contemporary childbirth model as a paradigm of power and control. This paradigm positions pregnant and birthing women at one end of this continuum and male dominated institutions (hospitals) and professions (medicine) at the other. One of the primary ways this is achieved is via authoritative knowledge. For any particular domain, writes Jordan (1997), several knowledge systems exist. Some of these knowledge systems come to carry more weight than others, "...either because they explain the state of the world better for the purposes at hand...or because they are associated with a stronger power base" (Jordan, 1997, p. 56) and usually both.

Power is a direct result of systems of authoritative knowledge, with medical professionals automatically having more power and control than patients and birthing women, simply because they hold medical knowledge (Crossley, 2007), and because medical knowledge is so highly valued in Western countries (Foucault, 1989/ 2003). Technology goes hand in hand with medicine in this regard, for in the hands of medical professionals, technology-and the authority to use it-is an extension of their power (Suchman \& Jordan, 1997).

One of the ways a birth in the biomedical system is categorised from the early stages of pregnancy is in terms of risk. "Risk" is not a neutral term, and assumes the body is always on the brink of failure irrespective of circumstances, and almost always includes negative consequences for women (Lane, 1995, p. 57). The authoritative knowledge of the medical model of childbirth means that "normal" is defined in medical terms, and is often only used in retrospect, thus making every pregnancy "at risk" until after the birth (Skinner, 2002). The routine assignment of risk to pregnant women occurs without taking into account structural and social conditions, which individualises the risks, and in turn legitimises the routine of interventions (Lane, 1995, p. 55). This has seen the routine use of interventions like induction and foetal monitoring, which has done little to improve the outcome of "high-risk deliveries", and that some say can only be explained by the practice of defensive medicine (Cahill, 2001; Davis-Floyd, 1993/2008; Skinner, 2002). More recently however, the medical model of hospital birth has increasingly included the recommendation of doulas (birth attendants), and complementary and alternative medicine in 
pregnancy and labour (Harding \& Foureur, 2009; Hastings-Tolsma \& Terada, 2009; Wiebelitz, Weyert, \& Beer, 2009), expanding the medicalised model to incorporate a variety of practices that might contribute to a more positive birth experience.

There is an obvious dichotomy set up in the childbirth literature between "medicalised" and "natural" definitions of childbirth. These two concepts however, rely on each other in a birthing context. What counts as medicalised depends on which elements of nature are being dominated, and similarly what counts as natural depends on what elements of medicine are excluded. A common understanding of "natural" is a birth without technological intervention, including spontaneous labour without anaesthesia, and a vaginal delivery. Crossley (2007) extends this definition, seeing "natural" birth as a subjective re-enactment of nature, which produces a physiological rather than pathological experience. Discursively there has been a move toward using terms such a physiological birth and normal birth, rather than natural birth (Downe, 2004).

There is an increasing body of literature that focuses on childbearing and broader issues of space and place, rather than with a focus on medicalisation. Hospitals and birth have been critiqued in relation to geographical (Abel \& Kearns, 1991), spatial (Fannin, 2003; Michie, 1998; Seibold, Licqurish, Rolls, \& Hopkins, 2010), and design (Foureur et al., 2010) frameworks as well. The focus for much of the research on homebirth is focused on the importance of issue such as gaining autonomy by birthing outside of the medical system (Dahlen, Barclay, \& Homer, 2008; Edwards, 2005; Jackson, Dahlen, \& Schmied, 2012; Nolan, 2011). Perhaps one reason for this is the high representation of midwifery scholarship in home birth research.

In Australia, home births can be achieved in three distinct ways. Firstly, a pregnant woman may birth unassisted, that is, without the assistance of a midwife or obstetrician, or any childbirth professional. This is referred to as unassisted childbirth (UC), or free birth. Secondly, she may hire an independent midwife, for a fee of between AUD\$3000 and AUD\$5000. This midwife will usually oversee all antenatal care, will attend the birth and provide postnatal care as well. Thirdly, depending on the geographical location of the pregnant woman, she may be eligible to participate in a hospital home birth program. These programs typically operate via a "case-load" model, where two or more midwifes are assigned women to oversee their care from initial enrolment into the program, antenatal care, childbirth in the woman's home, and postnatal care. The antenatal care takes place in the hospital, and the assigned midwives attend the birth in the woman's home. These programs are government funded, and have strict eligibility guidelines (see Catling-Paull, Foureur, \& Homer, 2012), which the pregnant/birthing woman must comply with or her participation in the program will be cancelled. These programs are relatively new in Australia, the first being established in Perth, Western Australia in 1996, but most since 2005 (Catling-Paull, Coddington, Foureur, \& Homer, 2013). These programs are becoming increasingly popular, with 12 hospitals nation-wide offering publicly funded programs (Catling-Paull et al., 2013). While the efficacy of such programs is beyond the scope of this article, the research on these programs offers compelling evidence of their success (Catling et al., 2014; Catling-Paull et al., 2012; McMurtrie et al., 2009).

The safety of home birth for low risk women has been long-established, and has been used as the primary rationale for the implementation of publicly funded hospital home birth programs in Australia (Catling et al., 2014; Catling-Paull et al., 2012). While research on the experience, impact, and importance of space when it comes to childbirth is growing, the focus remains primarily on hospital space (Fannin, 2003; Foureur et al., 2010; Hammond, Foureur, Homer, \& Davis, 2013; Smyth, Payne, Wilson, \& Wynyard, 2013).

For the Australian women I interviewed, having a birth in the home necessitated an at least temporary reshaping of the meaning of home. The existing ways the home was used by those living within it, and those visiting, needed readjusting to allow for the changes a home birth would instigate. These changes were as temporal as pregnancy and childbirth, but were important to creating balance for the participants. The home for home birthing women is indeed a physical place in which they live, but it also becomes a space that embodies various imaginings, and becomes intimately connected to the experience of pregnancy and childbirth.

For childbirth, part of what defines the home is its ideological distance from the hospital, meaning the hospital is a necessary component in the discussion of the home in home birth. There also needs to be caution when conceptualising the home, so as to not represent it as an entirely positive place or experience, as some of the participant narratives in this paper will show. Recent conceptions of home go beyond the configuration of a physical, spatial entity and into more of "...an idea and an imaginary that is imbued with feelings" (Blunt \& Dowling, 2006, p. 2). The imaginary in question includes a nostalgia for the past (Chapman \& Hockey, 1999), our expectations of the present, and our dreams (and fears) for the future (Blunt \& Varley, 2004).

Significantly, there are a myriad of ways in which being "at home" could be alienating. The geographical literature on home is right to criticise definitions that rely on notions of sanctuary, security, and safety. For many people home is not, as they say, "where the heart is", but a place of alienation, discomfort or violence. Home, therefore, requires a contextually based definition, one that works for specific situations and groups of people with whom that definition may be 
relevant. The home as a place of birth may only seem relevant to a small group of families who can afford it and for whom this is their reality, but it is nonetheless an important way to indicate the ways in which definitions and pre-existing ideas of home may be reshaped depending on the context.

While the home would ordinarily be considered a private sphere of social life, the influence of public life is keenly felt at home. Since the nineteenth century, the home afforded the possibility of retreat from public view, despite it not, in practice, being a place escaping the public gaze (Chapman \& Hockey, 1999, p. 10). Blunt and Dowling (2006) write that the home is best understood "...as a site of intersecting spheres, constituted through both public and private" (p. 18). In the case of home birth, public discourse, which includes legislation regarding midwifery and home birth, heavily impacts the experiences of childbirth in the home. The public realm of policy seeps into the intimate spaces of the home, producing a home that has become politically, socially and even morally contentious and very, very public.

The emergence of publicly funded home birth programs, and a continuing critique of medical knowledge is indicative of Giddens' (1991) assertion that in highmodernity multiple discourses compete for authority. The very fact that these knowledge sets compete at all is only possible in contexts where each set is considered equally ideologically valid. As such, it is not just home birth consumers questioning the authority of medical discourse and birth choices, but hospitals are increasingly encouraging and facilitating the use of more holistic birth approaches.

\section{Methods}

The data presented here forms part of a larger study on spirituality and home birth experiences. The themes presented here are from a small cohort of participants who spoke about their homes in their narratives as key sites of renegotiation. While the number of participants presented here is small compared to the number of women interviewed for the larger study, they speak directly about the gap in the empirical knowledge base outlined above, namely; space and the role home spaces play on pregnancy and birth experiences.

Participants were recruited via online parenting forums, where the author contacted the administrator with information about the research, and asked permission to write a post in an appropriate thread to recruit participants. This post included information about the research, eligibility criteria, what participating would involve, and the author's contact details. Eligible participants would be both currently pregnant and planning a home birth, or would have had home births in Australia in the last three years, or be a practicing doula or independent midwife. Snowball sampling also occurred as a result of these posts, and within a period of 30 days over 200 eligible participants from around the country had contacted the author. While most of the participants lived within three hours of a capital city, it was decided for reasons of time and travel convenience that participants in QLD and VIC would be relatively central to Brisbane and Melbourne, while Sydney, where the author resides, was more spread out, and as a result there were participants from the Blue Mountains, the Illawarra, and various suburban Sydney areas. The number of eligible participants who lived in these areas and were available for face-to-face interviews on the travel dates arranged totalled 58.

In-depth interviews took place in 2010, and participants were asked narrative-style questions, including "can you tell me about the day you found out you were pregnant" and "can you tell me your birth story?" Interviews were recorded and transcribed, and coded initially for thematic results and then for a more detailed discourse analysis (Tonkiss, 2004). All names in this paper appear as pseudonyms. I interviewed all but four women in their homes, and for the other four one was in a local café, and three others were in the homes of their friends, also participating in the study.

Of the 58 women who participated in this study, 51 were pregnant and planning or had had a home birth in the last three years. The other 7 were professional doulas and independent midwives. Of the 51 home birthing women, 41 had had previous hospital births, and of those hospital births, 5 were caesarean births. The participant demography in this study is reflective of those found in other western countries, including the United States (Klassen, 2001), Sweden (Anthony, Buitendijk, Offerhaus, van Dommelen, \& van der Pal-de Bruin, 2005), and New Zealand (Abel \& Kearns, 1991). The participants could be described as predominantly middle-class, self-identified as Caucasian Australians, many were tertiary educated, all had access to the Internet and were widely read when it came to childbirth literature. Below are tables (Tables 1-4) indicating age, household income, education, and religion.

White women occupy a privileged position in birthing culture, and it is within this privileged position that Australian birthing discourse rests. The voices of this research are also predominantly white, though the value of this research has implications for childbearing more broadly. By better understanding the complexity of the experiences of home birth, broader childbirth discourse can begin to expand and take into account the myriad of peripheral experiences.

The aim of this study is not to provide generalised results or findings, but rather to move the theoretical debate beyond the home/hospital dichotomy. Further studies could expand the sample size to address the lack of ethnic and cultural diversity of participants in this study. 
Table 1. Participant age range.

\begin{tabular}{ll}
\hline Age Range & Number \\
\hline $18-25$ & 3 \\
$26-35$ & 28 \\
$36-45$ & 19 \\
$46-55$ & 1 \\
$55+$ & 1 \\
No Response & 7 \\
Total & 59 \\
\hline
\end{tabular}

Table 2. Completed education level.

\begin{tabular}{ll}
\hline Education & Number \\
\hline Some High School & 1 \\
High School & 11 \\
Undergraduate & 19 \\
Post-Graduate & 6 \\
Vocational Training & 12 \\
No Response & 10 \\
Total & 59 \\
\hline
\end{tabular}

Table 3. Total household income.

\begin{tabular}{ll}
\hline Household Income & Number \\
\hline under 25k & 3 \\
$25-39$ & 2 \\
$40-49$ & 2 \\
$50-74$ & 15 \\
$75-99$ & 11 \\
$100+$ & 13 \\
No Response & 13 \\
Total & 59 \\
\hline
\end{tabular}

Table 4. Self-identified religious affiliation.

\begin{tabular}{ll}
\hline Religion & Number \\
\hline No religion & 29 \\
Christian & 10 \\
Catholic & 3 \\
Spiritual & 5 \\
Ba'hai & 1 \\
Buddhist & 1 \\
Mormon & 1 \\
Pagan & 1 \\
No response & 8 \\
Total & 59 \\
\hline
\end{tabular}

\section{Findings}

During the data collection and early analysis phase of the research, it became clear that, as previously discussed, the home is a taken-for-granted concept in home birth research. For most of the participants, home was spoken of as a relatively stable concept, however in a small number of narratives there was a clear renegotiation of the experience of home as a result of pregnancy and birth, and it is on those narratives this paper is based. This is not to generalise the experience of home, but rather to illustrate the more conceptual issue of the importance of space and place to childbearing beyond the experience of hospital space.

The central themes of place and space, and the experience of boundaries were common themes in the interview data. I have chosen only 5 of the 58 narratives for this paper, and have done so on the basis of the rich description they provide about the relationship between home and childbirth. The participants spoke as passionately about home birth as a choice as they did about their homes in relation to their births. Invariably, every woman I spoke with discussed the decision to birth at home, and while these decisions were so subjectively distinct, they involved issues like previous birth experiences, friends' birth experiences, what they had read, online data and statistics about childbirth, and issues of cost and practicality. The central issue among the many discussed was always whether home was right. The importance of place in this decision was particularly strong, especially during the early, decision-making phase of planning a home birth. Secondly, the comparison between home and hospital environments were often discussed by women who had had previous births in hospitals, however it was the need for, and implementation of, previously un-required boundaries in and around the home that was a key concern leading up to the birth. Spaces that had not previously required monitoring suddenly needed rules, and those in their lives who had not previously had restricted access to their homes, were given, and expected to respect, new boundaries. Home spaces took on sacred significance within the home, heightening the intensity of feeling for previously usual living space.

\subsection{Place and Space}

Having a home birth is not as simple as birthing "at home". Place is of the utmost importance in the decision to birth at home. Where women reside at the time of their pregnancies can often be reason enough not to have a home birth. Birthing at home should be seen as part of a broader social and cultural movement in Australia toward sustainability and environmental awareness, culminating toward a general consensus that the more natural something is, the less mass produced, the more local, the better it is.

As the below narratives will indicate, the decision to birth at home includes considerations of the home space and ones connection to it. Where that connection is strong, the decision seems easy, but when it is not, it is fraught.

Rachel was pregnant with her second child when we met. Originally from New Zealand, Rachel and her 
husband were both living in Australia while they pursued tertiary studies. Rachel had her first child in a public hospital in Canberra, ACT, not long after moving to Australia. Now living in Western Sydney, Rachel was planning a home birth through a publicly funded local hospital program. When telling me about the decision to use this program, she said:

if we could afford to have an independent midwife I would have gone that way from the beginning. So yeah that was why we ended up doing it, because it was free and I don't know if I'm passionate about it enough to pay $\$ 4000$ for it, especially since we don't-this isn't our land, you know? This is this is just where we rent an apartment. We're not going to be here forever, it doesn't have that kind of emotional meaning that it would if we gave birth in New Zealand, in our home town and our place, our place that we bought...If we had a home like that, or even at my parents place or something that we were connected too? Yeah maybe then I'd be willing to pay for it, but here it's just like convenience and control over your own birth really.

The relationship between place, home and value are brought to the fore here. The $\$ 4000$ cost of a home birth with an independent midwife becomes a question of value, a value that is not, for Rachel, met in her Western Sydney apartment. Her connection to New Zealand however, would make the value of home birth worth the cost. It seems clear that for Rachel, New Zealand is home, and her apartment is just where she lives. It is unclear whether Rachel would have pursued a home birth had the hospital program not been available to her, though her reference to the cost of hiring an independent midwife, and whether a home birth is worth the cost suggests it may not have been a choice she would have made. Expressing the need to be at home in order to have control over her birth draws on common home birth rhetoric. By using a publicly funded hospital program, Rachel is able to mitigate the expense of hiring an independent midwife with the value and worth of birthing at home. These programs are an increasing option for women who are unable or unwilling to pay the cost of independent midwifery, but can still safely birth at home.

Several women expressed a deep attachment to the place in which they either planned to give girth, or where they did give birth. For Nina, two years after the home birth of her son, she still felt connected to the rental house in which he was born. Talking about how she felt as her due-date approached, she said:

I think towards the end there was a lot of stress about where I was going to birth because we were moving. I actually couldn't picture myself birthing in this new house, and so [baby] actually came three weeks early, three days before we were supposed to
move...And at the time [midwife] was saying "I think you're going to have the baby today", and I was saying "but we're in the wrong house and I can't move because we haven't finished painting yet and all the towels are at the new house and I can't birth here", but then when I really thought about it...l'd been trying to picture myself birthing in the new house and I hadn't been able to.

Nina told me she had spent a lot of time in pregnancy visualising going into labour, and doing relaxation breathing based on those visualisations, and the rental house was always the place in which she visualised. Via spiritual practices such as meditation and visualisation, Nina made a psycho-spiritual connection between her pregnant body, her baby, and the rental home, a connection that, after the months of pregnancy, was particularly strong. This connection was interrupted with the purchase of the new house and moving plans, causing a clearly fraught decision making process when she went into labour early. Despite birthing in the rental house, as she had planned, Nina said:

I feel really sad in a way that it wasn't our home that we own, it was in our rental place. I feel really sad every time I drive past there, like a real kind of connection to that house, and I feel sad that he's not going to grow up in the house that he was born in. But at the same time I kind of can see why I needed to birth there...that had been the plan until we suddenly bought this house, so that had been the plan most of the way along. And that's where I pictured myself when I was doing visualization and stuff...and also [baby] knew that was the plan.

Decisions about birth and space are complex and involve interplay between practical, emotional and spiritual factors and perceptions of birthing women. For Nina, having two homes when she actually went into labour dislodged her planning-both practical and emotional/spiritual planning, and the decision no longer became one of birthing at home, but birthing in the place that felt most like home at the time, her rental. Here the space between home and house is particularly strong, and it is clear that for Nina, she was planning a home birth, and as such feeling connected to the surrounding space was the most important thing.

Similarly, the conflict between home and connection to place was also played out with Fenay, who had a free birth for her first child, and when she became pregnant the second time, she was living in a different town, several hundred kilometres away. In talking about the birth of her second child, she said

We ended up out in [small town] which is a hole! Living in an awful flat that looked out into the bins of the supermarket, so I didn't want to have a baby 
there, so we went over to the hospital.

The juxtaposition between contamination and cleanliness is at the forefront here, as Fenay recalls the view from the flat overlooking the supermarket bins, which is said together with calling the town a hole, and describing her flat as awful. These emotive descriptions of this space are given as the reasons she went to hospital. The hospital, in this context, "solves" the problem Fenay has with the town and the flat, and the contamination of the flat by the proximity to the supermarket bins. The hospital becomes the symbol of cleanliness, a pure, sterile environment that trumps the home when the home is contaminated. Fenay illustrates that it is not simply being at home that is important for home birth, but being in a space one can feel safe in, and a space that is worthy of the importance of childbirth. Dirt, it would seem, or proximity to the dirt of consumerist waste-the supermarket bins-has little place in this scenario.

Fenay lived in a town near a world heritage national park in New South Wales when she had first and second children. When pregnant with her first child, she said:

I used to really like sitting on rocks and sitting. Just sitting in nature. And I liked to be out in the bush a bit when I was pregnant, too...that kind of spiritualness, that connection to the earth kind of spiritualness, your understanding of the world.

Living there was a source of spiritual connection for Fenay, a place of nature and thoughtfulness. This directly contrasts to the way she describes the small town of her second pregnancy. This makes clear it was not only the "awful flat" that contributed to her feelings about not wanting to have a baby there, there was a bigger picture of the importance of feeling a connection to place as a way of justifying birthing at home. The concept of home itself is expanded beyond the physical and into the broader geographical space, and also the psychic realm of connection. Certainly, for van Muren (1990), the experience of lived space is largely pre-verbal, and thus difficult to describe and/or explain.

The home Fenay birthed her first child in, unassisted, contrasts greatly to where she lived while pregnant with her second child. For her third child, Fenay and her family were once again in the National Park setting of her first birth, where she once again birthed unassisted. The contamination of her flat while pregnant with her second child could be extended to the distance from the more nature-based spirituality reflected upon in the narrative of her first and third children's' births.

The importance of nature is a strong element in home birth discourse, with "natural birth" being one of the tenants of home birth rhetoric. Indeed the term "natural" on its own has become an umbrella term for a critique "...aimed at various crises of modern Western society, from industrialism, capitalism and materi- alism, to urbanisation and mass culture" (Moscucci, 2003 , p. 168). Natural birth is a strong theme in home births-as a concept it is used much in the same way as home is to hospital, it is perceived as the opposite of medicalised experiences. "Home birth" has become discursively synonymous with "natural birth", and thus much of the critique Moscucci mentions can be readily extended to include hospitals and medicalisation. In this sense, "home birth" as a movement can be seen as part of a growing social continuum that prioritises an ecological, sustainable worldview, which influences decisions surrounding pregnancy, childbirth and parenting as well as social life more broadly.

As part of this rhetoric, the importance of place is expanded from the expectations of home as the place to give birth to knowing whether the home is right for birth. One of the ways this is achieved is by introducing new ways to interact with the home space. The next sections will explore the changing dynamic that is created when birth takes place at home.

\subsection{Boundaries}

None of the women in this study had accidental home births; they were all carefully planned or in the process of being planned. This deliberacy also extended to the space within the home that they hoped or intended to actually give birth, many literally altering part of their home for it. Many of the women interviewed referred to the place of birth as a space rather than a room. Many of these areas had functions other than birthing, such as the room usually designated as the office, or bedroom, or even the dining or living rooms. With new configurations, new uses and new meanings, there comes the need to find new ways to protect such spaces, with a focus on the temporality of birth, and the heightened need for protection during this time. As such, a recurring theme in participant narratives was the need for respected boundaries. Ordinary means of ensuring the boundaries between the world and the home space become insufficient and there is need for something more intimate, private and specific for birth.

Laurel lives in Brisbane, Queensland. She has three children, the youngest was only a few months old at the time I interviewed her. Her first child was born in hospital with intervention, and with her second child she was looking for something more woman-focused and natural, so she went to a local birth centre. For her third pregnancy, she started going through the birth centre again, but found it was no longer the one-toone care she felt was important, so she hired an independent midwife and started planning a home birth. When talking about the sort of things she did to get ready for the birth, she said:

I knew that I wanted it to be dark, and to be private, and I didn't want anyone to-I was concerned about 
my mum turning up, or someone turning up, so I just did everything to avoid me being disturbed. And I put signs up on the front step and the door saying "if anyone comes and we don't come, we're busy having a baby" or, "we're in bed with our baby-we love you and we'll call you later". So just to put a boundary in place so I could let that feeling go and just get on with having a baby.

The shift between speaking for herself, and speaking for the family indicates at least her perception of the family's mutual instigation of boundaries to protect their privacy during the birth. In a hospital environment, the policing of boundaries are largely governed by predetermined rules. Visiting hours create clear and often strict guidelines between the rest and privacy of new parents and visitors. At home, these boundaries are less clear and need to be instigated and enforced by the families themselves. This requires new methods of not only relating to the space of the home itself as a site of safety and security, but also of relating to others within the home.

These issues were reiterated by Taren, who told me the story of the birth of her second child, her first home birth. She described how she felt in the days after the birth,

At home, in one way you can feel a bit protected because it's your home, but other times you feel like [family] just walk up the back, and I kinda feel a bit exposed, and so I am aware of that as well. And I know I need to be a little more assertive this time around and [husband] needs to be more assertive too in saying what feels okay for us at the time, whether we have visitors or not and how long they might stay. Cause I did find that tiring, with certain people kind of staying a bit too long just only after a day or two and thinking, well you know, other people would still be hospital right now having bed rest-not that I feel like I need to be treated like a patient-I felt kind of pressured to like be dressed up with makeup and making cups of tea and hosting people cause it was my house, whereas in hospital you wouldn't be expected to do that. You would just be lying in bed with your pyjamas on cuddling the baby. But at home I kind of felt a bit sort of guilty in some way that I wasn't up making everyone cups of tea and lunch

The switch between first and second person narration here is reflective of the narrative shift between personal experience story-telling of the former and the generic truths of popular attitudes, beliefs and values of the latter (Georgakopoulou \& Goutsos, 1997/2004, p. 27). For Taren, this narrative begins with the situated truth of feeling protected in one's home, but then moves to contrast this feeling when "[family] just walk up the back", the "just" here indicating a culturally specific, "common sense" boundary-a boundary not only understood in the context of cultural home making in Australia, but also the shared understanding between Taren and I at the time of the interview. She then moves into a more personal account of her postnatal experience at home, then shifts again into a shared understanding of what would be expected of a new mother in hospital. This is not only reflective of Taren's knowledge of cultural birthing norms, but also of the shared knowledge between us in the interview setting. Taren speaks to me comfortably in the assumption that I, too, would not expect a new mother to be wearing make-up and playing host. She then switches back into first person, admitting her guilt for not living up to the expectations that she knows are unreasonable.

The conflict illustrated here between the expectations of a female host, and the experience of having just birthed a baby at home, and the lack of understanding from her family regarding this suggest that it was the expectations that were in need of boundaries rather than the visitors themselves. Taren directly implicates her husband's role in this also, saying he needs to be more assertive in what he thinks is OK. The authority of policing these boundaries is on him, while the burden of the expectations is on Taren.

Narratively it is noteworthy that this passage comes after the actual birth story of her son, and after she spoke about the ways she created her birth space and the way in which the literal construction of this space was influenced by her birthing prerogatives. The power and authority over her home before birthing decreased once the space converted back into usual living space, post-birth.

The contrast between home and hospital in this passage is unique; it was one of the few times I encountered positive representations of hospital space. What Taren is referring to here however, is not the hospital space per se, but rather the protection of hospital boundaries, and the acceptance of hospital authorised visiting time protocol within a maternity ward, which often have strict visiting hours. At home, however, there are no such protocols in place.

Though not in reference to visitors, Rachel's story also reflected the need for authority over the home, as she spoke about the plans for the birth of her baby. Two midwives were assigned to her via the hospital program, and Rachel was unsure how "hands off" they would be, considering they were used to hospital births. She said

If they really annoy me then I could just say-just leave and go and wait in the car until I call you, you know because I think there is that power in your own house that it, it's actually your space and you have that whereas when you're in the hospital and you're in kind of their space but yeah. 
Here the boundary is a perceived, anticipatory one. Rachel was still pregnant during our interview, so she is talking about what she could say should the midwives "annoy" her, but Rachel indicates a boundary between her space and her authority in that space. Her reference to being annoyed clearly indicated that Rachel has a set of expectations that contrast with her perceptions of midwives behaviour in a hospital setting. Should these expectations not be met, as she has anticipated, she has a plan in place.

Rachel uses the first person when talking about these plans, reflecting the independence with which many women plan their home births. While partners are certainly part of the decision making process, ultimately the woman organises and plans most of what will take place. From buying/acquiring the items needed to the preparation of the birth space, women are the primary decision makers (Lindgren \& Erlandsson, 2011). For childbirth in hospitals, research with midwives has argued that the birthing space for women does not belong to her in the moments of birth, but is "lent" to her by the hospital (Seibold et al., 2010). In home birth however, a birthing woman takes ownership of the space she holds while in labour, regardless of the usual "owner" of that space-whether it be joint ownership of communal living spaces, children's play spaces, or a partner's office space. She has prearranged with the family to be able to move freely around the space that has been dedicated to her and the birth.

\section{Conclusion}

Whether boundaries are physical, domestic or hypothetical, they function to reinforce balance between the pregnant/birthing woman and her home space. The cultural transgression of childbirth at home in Australia brings with it new challenges for women and their homes, challenges that may not have been met before. Childbirth drastically calls into question the existing relationship between women and home, and both women and home undergo an at least temporary transformation in relation to the other. The home space comes to accommodate a new set of needs and expectations, and the birthing woman and her family renegotiate their positions within this space as well.

Viewing home birth in a broader social and cultural sense opens the possibilities of "knowing" the home and birth beyond the confines of residence and medicine respectively. The impact of a focus on space and place in home birth experiences directly responds to the growing literature on therapeutic landscapes, with places and spaces moving beyond geographical location/social contexts of places, and into a more holistic understanding of the meaning of place for people, and the impact these meanings have on health and wellbeing (Gesler \& Kearns, 2002; Kearns \& Gesler, 1998).

When medical language "dominates and constricts perception of the birth process...uterine contractility and cervical dilation are often discussed as if they occurred on a laboratory bench rather than in a woman's body". As part of medical discourse, this is a model of understanding that perceives women as victims of their reproductive systems and hormones, and it is one that defines pregnancy as inherently pathological-a clinical crisis worthy of active intervention (Cahill, 2001; Freund, McGuire, \& Podhurst, 2003). This biomedical preference for understanding women ignores the inescapable psycho-social elements of birth (Mansfield, 2008), and the important transition to motherhood (Cahill, 2001). In home birth discourse however, the medical discourse is considerably overshadowed by holistic, even spiritual language (Davic \& Davis, 1996). Part of the reason for this is the ideological as well as geographical distance between the home and the hospital. That the home would impact childbearing language and experience is telling of the importance of pregnant and birthing women's surroundings, and the impact place and space has on experience. This article really only begins to set out some of the conceptual tensions and complexities around the relationship between childbirth and home space, and more research is certainly needed to understand its intricacies.

The rhetoric of home birth as natural and womancentred played out strongly in the narratives I heard during the interview process. When deciding on the home as the place for childbirth, the home is constructed as not only preferable to the hospital, but as the ultimate place to have a baby. For the women in this study, childbirth and home are intimately linked, and as such the meaning of home must be conceptualised to incorporate the complexities that come with childbearing.

The "return" to home for childbearing should be seen as existing within a broader social and cultural movement in Australia toward sustainability and environmental awareness, an idea that the more "natural" something is, the less mass produced, the more local, the better it is. Viewing home birth in a broader social and cultural sense opens the possibilities of "knowing" the home and birth beyond the confines of medicalisation. The impact of a focus on space and place in home birth experiences directly responds to the growing literature on therapeutic landscapes, with places and spaces moving beyond geographical location/social contexts of places, and into a more holistic understanding of the meaning of place for people, and the impact these meanings have on health and wellbeing (Gesler \& Kearns, 2002; Kearns \& Gesler, 1998).

Continued focus on the home space in flux as a result of planning, having, and remembering childbirth at home reignites the discussion on home birth beyond discourses of safety and risk, which dominate the current debate. The temporal redefinition of living spaces via birth at home imbued those spaces with spiritual awareness. It is the space that creates a sacred experi- 
ence for childbirth, and not simply the decision to birth at home instead of the hospital. Drawing on the need to connect with the space in order to birth, as seen in the above examples, highlights the importance of space and place when it comes to childbearing, a discussion that extends beyond the hospital walls. By being as critical of the home space as we have been with hospital space, we can start to unpack the importance of the complex and intimate relationships with space, place and birth.

\section{Acknowledgements}

With gratitude, I acknowledge the helpful comments from Cristina Rocha, Alphia Possamai-Inesedy, Emma Waterton and Jacqueline Nelson on previous drafts of this paper, as well as the five anonymous reviewers for their feedback and suggestions.

\section{Conflict of Interests}

The author declares no conflict of interests.

\section{References}

Abel, S., \& Kearns, R. A. (1991). Birth places: A geographical perspective on planned home births in New Zealand. Social Science and Medicine, 33(7), 825-834.

Anthony, S., Buitendijk, S. E., Offerhaus, P. M., van Dommelen, P., \& van der Pal-de Bruin, K. M. (2005). Maternal factors and the probability of a planned home birth. BJOG: An International Journal of Obstetrics and Gynaecology, 112(6), 748-753.

Blaaka, G., \& Shauer, T. (2008). Doing midwifery between different belief systems. Midwifery, 24, 344-352.

Blunt, A., \& Dowling, R. (2006). Home. London and New York: Routledge.

Blunt, A., \& Varley, A. (2004). Introduction: Geographies of home. Cultural Geography, 11, 3-6.

Cahill, H. A. (2001). Male appropriation and medicalization of childbirth: An historical analysis. Journal of Advanced Nursing, 33(3), 334-342.

Catling, C., Dahlen, H., \& Homer, C. (2014). The influences on women who choose publicly-funded home birth in Australia. Midwifery, 30, 892-898.

Catling-Paull, C., Coddington, R. L., Foureur, M. J., \& Homer, C. S. E. (2013). Publicly funded homebirth in Australia: Aa review of maternal and neonatal outcomes over 6 years. Medical Journal of Australia, 198, 616-620.

Catling-Paull, C., Foureur, M., \& Homer, C. (2012). Publicly funded homebirth models in Australia. Women and Birth, 25, 152-158.

Chapman, T., \& Hockey, J. (Eds.). (1999). Ideal homes? Social change and domestic life. London and New York: Routledge.

Cresswell, T. (1996). In place/out of place. Minneapolis,
USA: University of Minnesota Press.

Crossley, M. L. (2007). Childbirth, complications and the illusion of "choice": A case study. Feminism and Psychology, 17(4), 543-563.

Dahlen, H., Barclay, L., \& Homer, C. (2008). Preparing for the first birth: Mothers' experiences at home and in hospital in Australia. Journal of Perinatal Education, 17(4), 21-32.

Davic, R., \& Davis, E. (1996). Intuition as authoritative knowledge in midwifery and homebirth. Medical Anthropology Quarterly, 10(2), 237-269.

Davis-Floyd, R. (1994). The technocratic body: American childbirth as cultural expression. Social Science medicine, 38(8), 1125-1140.

Davis-Floyd, R. (2008). The technocratic model of birth. In C. G. Helman (Ed.), Medical Anthropology (pp. 277-306). Hampshire: Ashgate Publishing Limited. (Original work published 1993)

Downe, S. (Ed.). (2004). Normal childbirth: Evidence and debate. Edinburgh: Churchill Livingstone.

Edwards, N. P. (2005). Birthing autonomy: Women's experiences of planning home births. London and New York: Routledge.

Fannin, M. (2003). Domesticating birth in the hospital: "family centered" birth and the emergence of "homelike" birthing rooms. Antipode, 35(3), 513-535.

Foucault, M. (2003). The birth of the clinic (3rd ed.). London and New York: Routledge. (Original work published 1989)

Foureur, M., Davis, D., Fenwick, J., Leap, N., ledema, R., Forbes, I., \& Homer, C. (2010). The relationship between birth unit design and safe, satisfying birth: Developing a hypothetical model. Midwifery, 26, 520-525.

Freund, P. E. S., McGuire, M. B., \& Podhurst, L. S. (Eds.). (2003). Health, illness, and the social body: A critical sociology (4th ed.). New Jersey: Prentice Hall.

Georgakopoulou, A., \& Goutsos, D. (2004). Discourse analysis: An introduction. Edinburgh UK: University of Edinburgh Press. (Original work published 1997)

Gesler, W. M., \& Kearns, R. A. (2002). Culture / Place / Health. London: Routledge.

Giddens, A. (1991). Modernity and self-identity: Self and society in the late modern age. Cambridge: Polity Press.

Hammond, A., Foureur, M., Homer, C., \& Davis, D. (2013). Space, place and the midwife: Exploring the relationship between the birth environment, neurobiology and midwifery practice. Women and Birth, 26, 277-281.

Harding, D., \& Foureur, M. (2009). New Zealand and Canadian midwives' use of complementary and alternative medicine. New Zealand College of Midwives Journal, 40, 7-12.

Hastings-Tolsma, M., \& Terada, M. (2009). Complementary medicine use by nurse midwives in the U.S. Complementary Therapies in Clinical 
Practice, 15(4), 212-219.

Homer, C., Thornton, C., Scarf, V., Ellwood, D., Oats, J., Foureur, M., Sibbritt, D., McLachlan, H. L., Forster, D. A., Dahlen, H. (2014). Birthplace in New South Wales, Australia: An analysis of perinatal outcomes using routinely collected data. BMC Pregnancy and Childbirth, 14(206).

Jackson, M., Dahlen, H., \& Schmied, V. (2012). Birthing outside the system: Perceptions of risk amongst Australian women who have freebirths and high risk homebirths. Midwifery, 28, 561-567.

Jordan, B. (1997). Authoritative knowledge and its construction Childbirth and authoritative knowledge: Cross-cultural perspectives (pp. 55-79). Berekeley, Cal.: University of California Press.

Kearns, R. A., \& Gesler, W. M. (Eds.). (1998). Putting health into place: Landscapes, identity and well being. Syracuse, NY: Syracuse University Press.

Klassen, P. (2001). Blessed events: Religion and home birth in America. Princeton, NJ: Princeton University Press.

Lane, K. (1995). The medical model of the body as a site of risk: A case study of childbirth. In J. Gabe (Ed.), Medicine, health and risk: Sociological approaches (pp. 53-72). Oxford, Cambridge: Blackwell.

Lindgren, H., \& Erlandsson, K. (2011). She leads, he follows-Fathers' experiences of a planned home birth. A Swedish interview study. Sexual and Reproductive Healthcare, 2, 65-70.

Mansfield, B. (2008). The social nature of natural childbirth. Social Science and Medicine, 66(5), 10841094.

McMurtrie, J., Catling-Paul, C., Teate, A., Caplice, S., Chapman, M., \& Homer, C. (2009). The St. George homebirth program: An evaluation of the first 100 booked women. Australian and New Zealand Journal of Obstetrics and Gynaecology, 49, 631-636.

Michie, H. (1998). Confinements: The domestic in the discourses of upper-middle-class pregnancy. In S. H. Aiken, A. Brigham, S. A. Marston \& P. Waterstone (Eds.), Making worlds: Gender, metaphor, materiality (pp. 258-273). Tucson: University of Arizona Press.

Moore, S. B. (2011). Reclaiming the body, birthing at home: knowledge, power, and control in childbirth. Humanity and Society, 35, 376-389.

Moscucci, O. (2003). Holistic obstetrics: The origins of "natural childbirth" in Britain. Postgraduate Medical Journal, 79, 168-173.

Nolan, M. L. (2011). Home birth: The politics of difficult choices. Oxon, UK: Routledge.

Possamaï-Inesedy, A. (2006). Confining risk: Choice and responsibility in childbirth in a risk society. Health Sociology Review, 15(4), 406-414.

Powell Kennedy, H., Nardini, K., McLeod-Waldo, R., \& Ennis, L. (2009). Top-selling childbirth advice books: A discourse analysis. Bith, 36(4), 318-324.

Putnam, T. (1999). "Postmodern" home life. In I. Cieraad (Ed.), At home: An anthrpology of domestic space. (pp. 144-152). New York: Syracuse University Press.

Rapp, R. (2001). Gender, body, biomedicine: How some feminist concerns dragged reproduction to the centre of social theory. Medical Anthropology Quarterly, 15(4), 466-477.

Reibel, T. (2004). The language of birth: How words colour women's experiences. Birth Issues, 13(1), 18-23.

Seibold, C., Licqurish, S., Rolls, C., \& Hopkins, F. (2010). "Lending the space": Midwives perceptions of birth space and clinical risk management. Midwifery, 26, 526-531.

Skinner, J. (2002). Love and fear: The midwife and her relationship with risk. Birth Issues, 11(2), 69-72.

Smyth, E., Payne, D., Wilson, S., \& Wynyard, S. (2013). The dwelling space of postnatal care. Women and Birth, 26, 110-113.

Suchman, L., \& Jordan, B. (1997). Computerization and women's knowledge. In P. E. A. a. D. Schuler (Ed.), Reinventing technology, rediscovering community: Critical explorations of computing as a social practice (pp. 97-105). Greenwhich, CT: Ablex.

Tonkiss, F. (2004). Analysing text and speech: Content and discourse analysis. In C. Seale (Ed.), Researching society and culture (pp. 367-382). London: Sage.

Van Muren, M. (1990). Researching lived experience: Human science for an action sensitive pedagogy. Ontario: Althouse Press.

Wiebelitz, G., Weyert, J., \& Beer, A. M. (2009). Use of complementary and alternative medicine in obstetrics. British Journal of Midwifery, 17(3), 169-175.

Williams, K., \& Umberson, D. (1999). Medical technology and childbirth: Experiences of expectant mothers and fathers. Sex Roles, 41(314), 147-168.

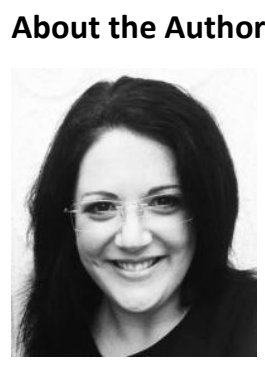

Emily Burns

Emily Burns is a PhD candidate at the Religion and Society Research Centre at the University of Western Sydney, Australia. Her research focuses on spirituality and home birth in Australia. 